\title{
Nature Clinical Practice Oncology: pound for pound a better choice!
}

\author{
Vincent T DeVita, Jr
}

I noticed an interesting letter in the 20 July issue of the Journal of Clinical Oncology. It was written by David M Mintzer and Lauren Chmielewski, from Pennsylvania hospital, Philadelphia. The point they make on the deluge of materials they receive each month is relevant to the mission of this journal and allows me the luxury of tooting our horn for a bit.

Let me quote directly from two of the paragraphs in the letter. Excluding subscribed journals, they say, "In July 2004, we received 205 individual communications of free unsubscribed medical information. Stacked, this material measured 12 inches high $(31 \mathrm{~cm})$ and weighed 14 pounds $(6 \mathrm{~kg})$. It included 10 peer-reviewed journals (640 pages), 7 newspapers (621 pages), and 18 non-peer-reviewed publications such as monographs, case reports, and symposia proceedings (261 pages) ... Additional communications included faxes summarizing cases or meetings, direct advertising for pharmaceutical products or devices, publications on practice management, treatment recommendations from insurers, and reprints sent by our pharmaceutical representatives following their office visits."

"Oncologists," they continued, "are being bombarded with unsolicited medical information in a variety of ways and from a variety of sources ... Most of these communications are sponsored by the pharmaceutical industry, which sends them out not only to educate physicians, but also to market and advertise their industry's products. Some of these communications come directly from the pharmaceutical industry but many are published by various third party organizations that are supported by the industry with varying degrees of control, input, and peer review."

Quite frankly, this sounds like the office of each and every one of us. And this illustrates the problem of trying to keep pace with the rapid progress of medical research. The authors of the letter point out that, not only is

\section{Nature Clinical \\ Practice \\ Oncology \\ was created \\ to solve this \\ problem....The \\ unique feature \\ of the journal, \\ however, is the \\ novel format \\ ....which is \\ appropriate to \\ the scientific \\ and medical \\ revolution \\ happening \\ around us.}

VT DeVita, Jr is the Editor-in-Chief of Nature Clinical Practice Oncology.

\section{Competing interests}

The author declared he has no competing interests.

www.nature.com/clinicalpractice doi:10.1038/ncponc0321 this unsolicited material expensive, but it also comes with certain biases toward products and issues that don't reflect the broad array of problems faced by most oncologists. They conclude, "we (with the exception of a few favorites) have taken to throwing the vast majority of it in the trash without reviewing it at all."

The journal Nature Clinical Practice Oncology was created to solve this problem and next month the journal will celebrate its first anniversary. In the editorial published in the first issue of the journal, in response to the question, "Do we need yet another journal?" I commented that physicians need some way of collecting information from this rapidly changing field in one highly reliable source if they are to remain up to date. This goal has been achieved, first and foremost, by careful selection of relevant materials by an outstanding Advisory Board and the extraordinary staff of the Nature Publishing Group. The unique feature of the journal, however, is the novel format. In addition to the viewpoints, overviews, and reviews of mechanisms of disease, all of which are relevant, we highlight and abstract important research articles from other journals. The most enjoyable articles, in my opinion, are the 'Practice Points', which have been very well received. These articles highlight, with a commentary from a prominent oncologist, original research articles that we feel may have a major impact on how we practice our craft. With the help of all our contributors we have now published over 80 Practice Points and, in total, over 140 fully peer-reviewed articles covering the entire breadth of the oncology field.

This novel experiment in medical journalism is far less costly to all involved, is unbiased and is appropriate to the scientific and medical revolution happening around us.

And it weighs a mere fraction of the weight of the material we all receive (and, by the way, mostly discard as well). 